\title{
Assessment of hepatic fibrosis by transient elastography in rheumatoid arthritis patients receiving methotrexate
}

\section{Nasrin Moghimi ${ }^{1,2}$, Khaled Rahmani ${ }^{2}$, Farshad Sheikhesmaili ${ }^{3}$, Asrin Babahajian ${ }^{4}$, Pezhman Sharifi ${ }^{5}$,} $\underline{\text { Samireh Ramezani }}^{6}$

1. Assistant Professor, Department of Internal Medicine, Faculty of Medicine, Kurdistan University of Medical Sciences, Sanandaj, Iran. ORCID ID: 0000-0002-9408-8431

2. Assistant Professor, Liver and Digestive Research Center, Research Institute for Health Development, Kurdistan University of Medical Sciences, Sanandaj, Iran. ORCID ID: 0000-0002-0860-8040

3. Assistant Professor, Liver and Digestive Research Center, Research Institute for Health Development, Kurdistan University of Medical Sciences, Sanandaj, Iran. ORCID ID: 0000-0002-4439-123X

4. Msc of Anatomical Sciences, Liver and Digestive Research Center, Research Institute for Health Development, Kurdistan University of Medical Sciences, Sanandaj, Iran. ORCID ID: 0000-0003-0278-1560

5. Msc of Microbiology, Sciences, Liver and Digestive Research Center, Research Institute for Health Development, Kurdistan University of Medical Sciences, Sanandaj, Iran. ORCID ID: 0000-0001-7953-9487

6. Assistant in Internal Medicine, Student Research Committee, Kurdistan University of Medical Sciences, Sanandaj, Iran, (Corresponding Author), Tel: +98-87-33247855, Email: samirehramezani@gmail.com ORCID ID: 0000-0002-6606-8089

\begin{abstract}
Background and Aim: Methotrexate (MTX) is commonly used in the treatment of diseases such as rheumatoid arthritis (RA) but, its hepatotoxicity potential, always has been a major concern. The aim of this study is to determine the rate of liver fibrosis by transient elastography (TE) method and its relationship with cumulative dose of MTX and duration of treatment, in rheumatoid arthritis patients receiving MTX.

Materials and Methods: This cross-sectional study included RA patients receiving MTX for more than 6 months. Hepatic fibrosis was determined by TE on the basis of the rate of liver stiffness. The patients were divided into 2 groups according to the results of liver stiffness measurement. Demographic, clinical and biochemical parameters were compared between the two groups. Correlation of the cumulative dose of MTX and duration of MTX treatment with the liver
\end{abstract} fibrosis was assessed.

Results: The study included 51patients, with a mean age of $52.53 \pm(9.95)$ years. $44(86.3 \%)$ patients were women. The cumulative dose of MTX was less than $4000 \mathrm{mg}$ in 45 (88.2\%) patients and more than $4000 \mathrm{mg}$ in $6(11.8 \%)$ patients with a mean treatment duration of $54.14 \pm(40.94)$ months. The median (IQR) value of liver stiffness was $4.70(3.60-5.50) \mathrm{kPa}$. The presence of liver fibrosis was detected in $11(21.6 \%)$ patients. There were no significant relationships between liver fibrosis and cumulative dose $(\mathrm{P}=0.21)$ of MTX and also duration of MTX treatment $(\mathrm{P}=0$. $30)$. The multivariate analysis demonstrated that only increased serum level of ALT was associated with presence of liver fibrosis $(\mathrm{OR}=1.07 ; 95 \% \mathrm{CI}: 1.01$ to $1.13 ; \mathrm{p}=0.01)$.

Conclusion: According to the results of this study severe hepatic fibrosis was not common in the patients who had received methotrexate. Increasing the duration of methotrexate administration and the cumulative dose of the drug had no effect on the incidence of hepatic fibrosis. Increased serum ALT levels in RA patients were associated with high rate of liver stiffness and increased risk of hepatic fibrosis.

Keywords: Hepatic fibrosis, Rheumatoid arthritis, Transient elastography, Methotrexate Received: May 12,2019 Accepted: Aug 27,2019

How to cite the article: Nasrin Moghimi, Khaled Rahmani, Farshad Sheikhesmaili, Asrin Babahajian, Pezhman Sharifi, Samireh Ramezani. Assessment of hepatic fibrosis by transient elastography in rheumatoid arthritis patients receiving methotrexate. SJKU 2020; 24 (6): 36-45

Copyright (C 2018 the Author (s). Published by Kurdistan University of Medical Sciences. This is an open access article distributed under the terms of the Creative Commons Attribution-Non Commercial License 4.0 (CCBY-NC), where it is permissible to download, share, remix, transform, and buildup the work provided it is properly cited. The work cannot be used commercially without permission from the journal 


\section{بررسى ميزان فيبروز كبدى با روش الاستوكر افى كذرا در بيماران مبتلا به آرتريت روماتوئيد}

\section{تحت در مان با متوتروكسات}

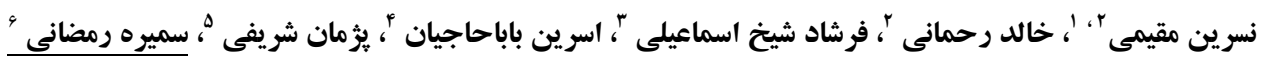

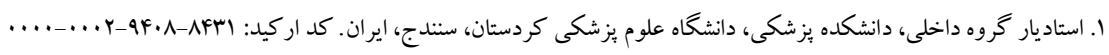

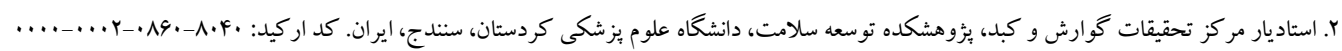

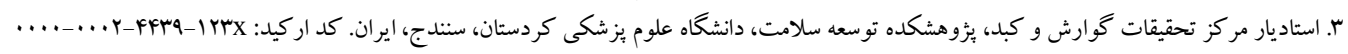

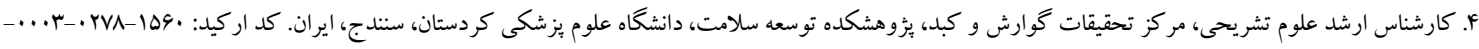

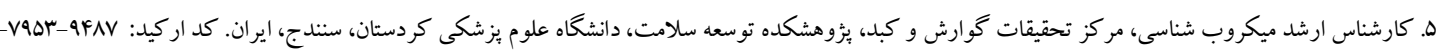
9. دستيار داخلى، كميته تحقيقات دانشجويى، دانشكاه علوم يزشكى كردستان، سندج، ايران. (مؤلف مسئول)، تلفـن ثابـت: samirehramezani@gmail.com

جكيله

زمينه و هدف: متوترو كسات، به طور عمده در درمان بيمارىهايى نظير آرتريت روماتوئيد مورد استفاده قرار مى گيرد، اما بتانسيل

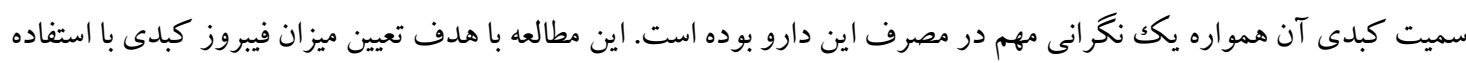

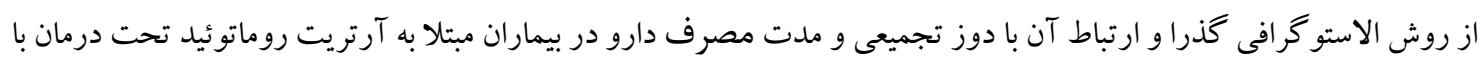
متوتر كسات انجام شده است. روش بر رسى: در اين مطالعه كه به صورت توصيفى - تحليلى (مقطعى) طر احى شده بود، بيماران مبتلا به؛ آرتريت روماتوئيد كه.

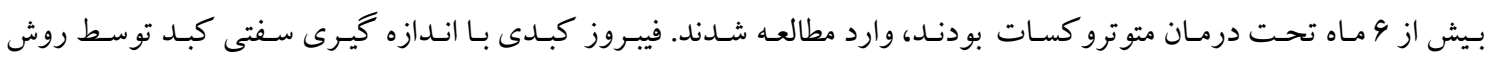

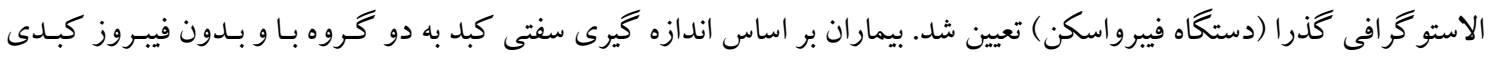

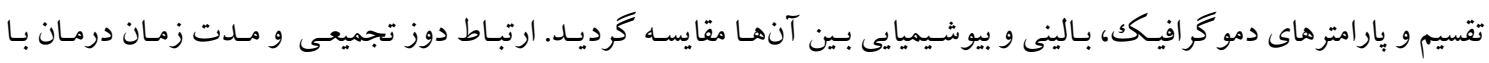

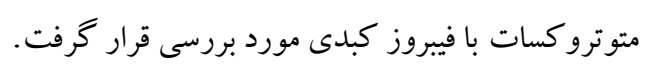

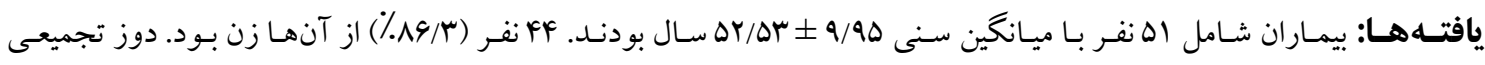

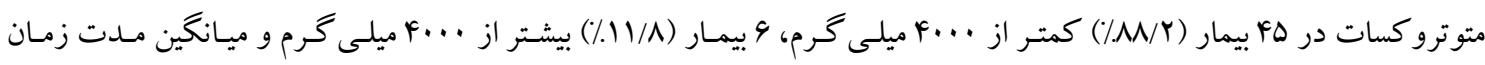

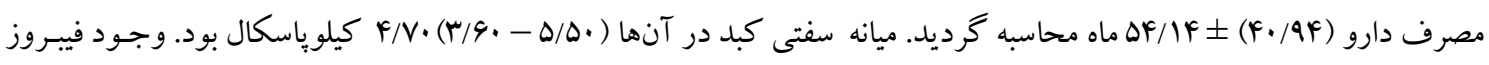

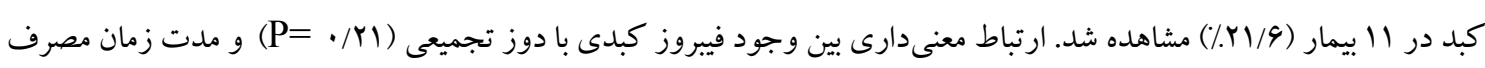

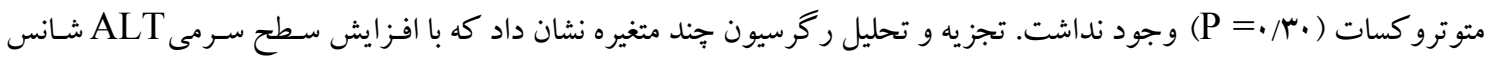

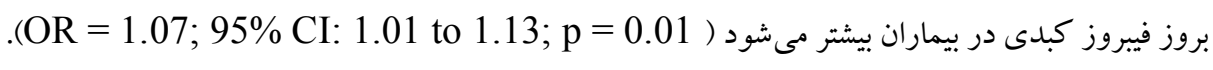

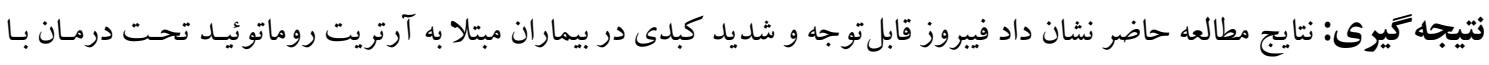

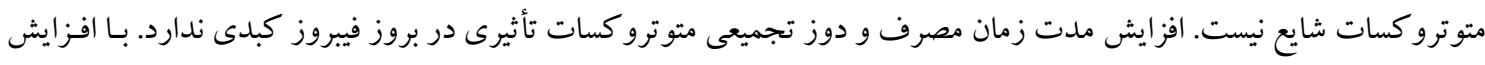

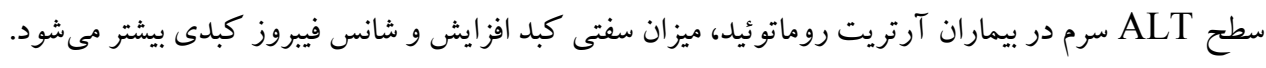

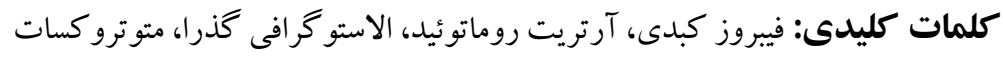

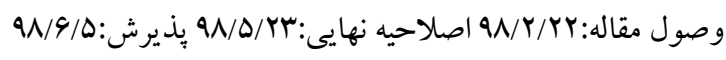


فيبروز كبد به وسيله روشهاى مختلفى شـامل تعيين سطوح ماركرهاى بيوشيميايى كبد (آنزيمهاى كبدى)، آزمونهـاى

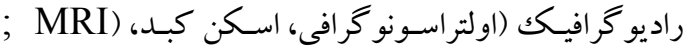
(Magnetic Resonance Imaging و آزمايشهـاى هيستوياتولوزى از طريق بيويسى كبد سنجيده مىشود.

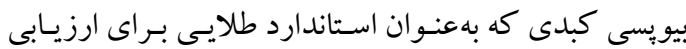

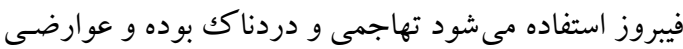

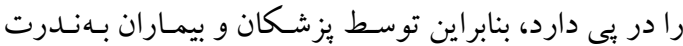
مورد يذيرش قرار كرفته و تكرار آن در افراد بـدون نشـانه بيمارى مشكل اسـت. از طرفى تستهـاى آزمايشكاهى بـهـ صورت جداكانه براى تشخيص فيبروز كبدى به اندازه كافى دقيق و قابل اعتماد نيستند (9). الاستو گرافى گذرا (Transient Elastography; TE) يكك روش جديد تصويربردارى هست كه اخيراً بهعنوان يكك روش دقيق براى تشخيص و ارزيابى بيشرفت فيبروز كبد در بيمارىهاى مزمن كبد شناخته شده است. اين

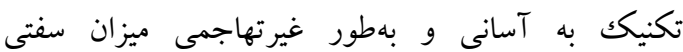
كبد (Liver Stiffness) را اندازه گيرى مى كند(·(1). در مطالعات انجام شده جهت پايش فيبروز كبدى توسط

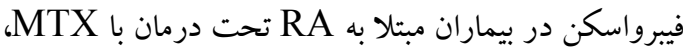
نتايج متفاوتى از ارتباط سفتى كبد با دوز تجميعى مصرف

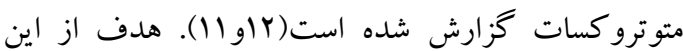
مطالعه بررسى ميزان فيبروز كبدى در بيماران مبتلا به آرتريت روماتوئيد تحت درمان با متوتركسات و ارتباط آن

با دوز تجميعى دارو و مدت زمان مصرف دارو است.

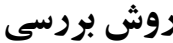

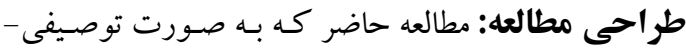

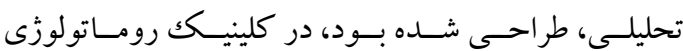
بيمارستان توحيد سنندج، اير ان از اسفند سال وهجا تـا بايـان

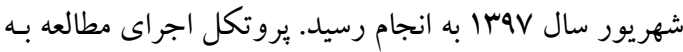

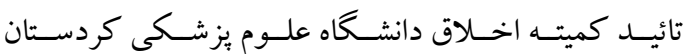

مقدمه

آرتريـت روماتوئيد (Rheumatoid Arthritis; RA) يـك بيمـارى التهابى مـزمن بـا تظـاهرات مفصلى و خـارج

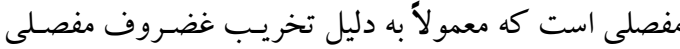

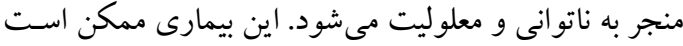

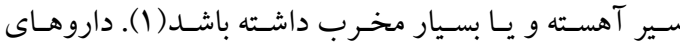
مختلفى كه جهت درمان اين بيمارى به كار گرفته مىشوند،

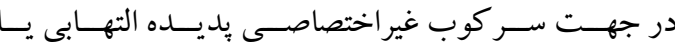
ايمونولوزيكك با هدف فرونشاندن يا محـدود كردن بيمارى

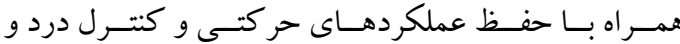
جلو گيرى از صدمه بيشرونده ساختمانهاى مفصلى، عمل

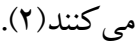

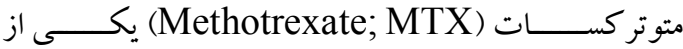
RA مؤثرترين داروهايى است كه بهور شايع بـراى درمـان و همجنين درمان لويوس، آرتريت بسورياتيك، ميوزيتهـا، واسكوليتها و بعضى بيمارىهاى ديخر روماتيسمى تجويز مىشـود (r). MTX، يـك داروى تضعيف كنــده سيستم

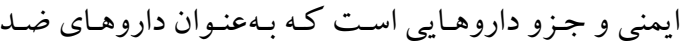
روماتيسمى تغييردهنده سير بيمارى (DMARD) شـناخته

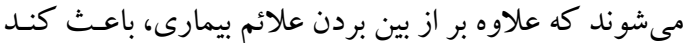
شدن سير بيمارى نيز مىشوند(هاءf). سميت كبدى و ايجاد فيبروز از عوارض اصلى در استفاده طولانىمدت اين دارو است( ). هر جند با كـاهش دوز دارو و تجويز هفتخى (ه تا ها ميلى گرم در هفته) به جاى تجويز

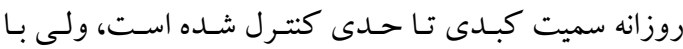
اين حال به دليل مصرف گسترده و طولانى مـدت ايسن دارو به خصوص در آرتريت روماتوئيد، موارد رو بـه گسترش از سميت كبدى ناشى از مصرف اين دارو مشـاهده شـده است كه در صورت بىتوجهى و ناديده كرفتن، مى تواند منجر بـــ

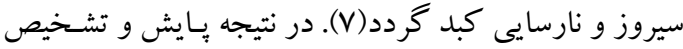
آسيبهاى كبـدى ناشى از متوتر كسـات در طـى دورههـاى

درمان ضرورى به نظر مىرسد(م). 
بروسـىهـاى يار اكلينيكـال: ميزان استئاتوز و فيبروز

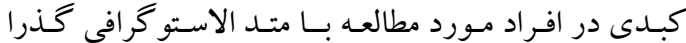
(Transient Elastography) فيبرواسكن(EchoSens, Paris, France) توسط فوق تخصص گو ارش مورد ارزيابى قرار گرفت نتايج فيبروز بـهـ

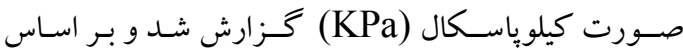
مطالعه Tsochatzis و همكــاران(IF) cutoff value

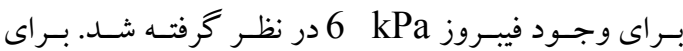
(CAP; Controlled

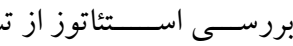
Attenuation Paramete) شده كه نتايج به صورت (dB/m) زَارش گرديد. سطوح

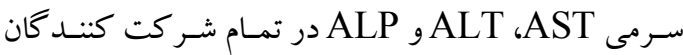
مـورد سـنجش قـرار گرفـت. همجنسين سـونو گر افى جهـت ارزيابى اكوزنيسيته كبد در بيماران انجام شد. آناليز آمارى: تجزيه و تحليل دادهها با استفاده از نرم افزار

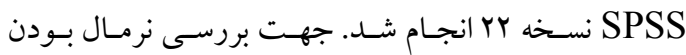

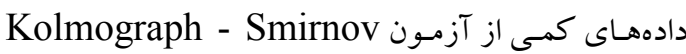

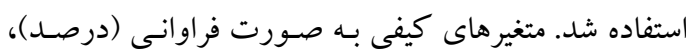

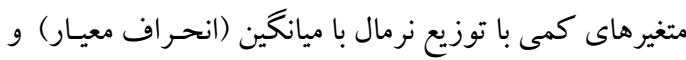

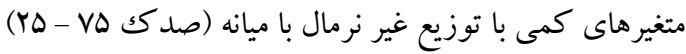

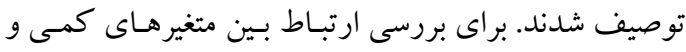
كيفى با فيبروز كبدى به ترتيب از آزمون t مستقل (يا معسادل نايارامتريكك آن يعنى آزمون مـن ويتنى) و آزمهون مجـذور

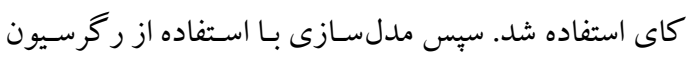
لجستيك براى بررسى روابط بين متغير هـا بـا هـدف كنترل

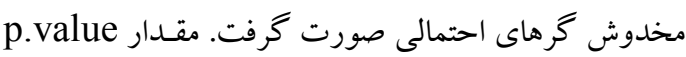
كمتر از هـ/• به عنوان سطح معنى دارى در نظر گرفته شد.

يافتهها

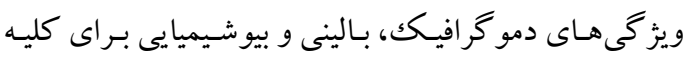
بيماران شركت كننده در مطالعه در جدول انشان داده شده

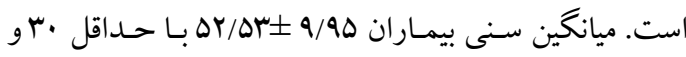

رسيد(No. IR.MUK.REC.1396/297). از تمـامى افر اد شر كت كننده در مطالعه رضايت آكاهانه اخذ گرديـد و

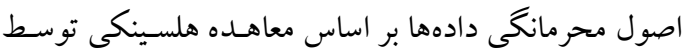

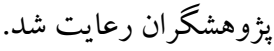
شر كت كنند كان: معيار هاى ورود بـه مطالعه شـامل افراد

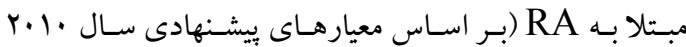
انجمـن رومــاتولوزى آمريكــا / اتحاديـهـ ارويـايى عليـهـ روماتيسـم (ACR- EULAR) (r))، تحـت درمـان بـا متوترو كسات كه بالاى \1 سال سن داشـتند و حسداقل 9 مـاه

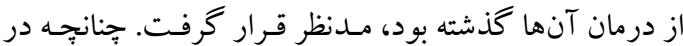
افر اد علائم و نشانههاى ديابت، سـابقه ابتلا بـه بيمـارىهـاى مزمن كبدى مانند هياتيتهاى ويروسى و اتوايميون، ايـدز، نارسايى مزمن كليه، نارسايى احتقانى قلب، سـابقه مصـرف

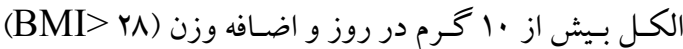
وجود داشت از مطالعه حذف شدند. روش نمونه گيرى بهصورت تصادفى ساده انجام شد و از بين مر اجعين داراى شرايط ورود به مطالعه بـا ايجاد جهارجوب لهادي نمونه گيرى و دادن شمارهاى به هر بيمار با استفاده از جـدول

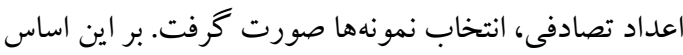
اله نفر بيمار وارد مطالعه شدند. جمع آورى اطلاعات دمو كر افيك و بالينى: داده هاى

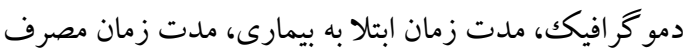

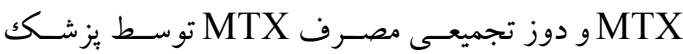

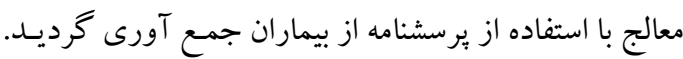
ميزان فعاليت بيمارى بر اساس فرمول DAS 28 سنجيجيده شد كه بر اساس تعداد مفاصل داراى تندرنس، تعداد مفاصل

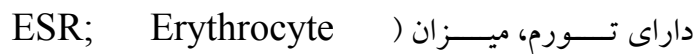
(Sedimentation Rate استفاده از روش (VAS; Visual Analog Scale) محاسبه و ثبت گرديد. فشار خون بر حسب (mmHg) نيز

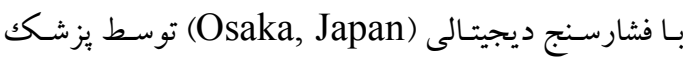
معالج در همه شر كت كنند كان اندازه گيرى شد. 
بيمار مشاهده گرديد. در يكك نفــ از ايـ لالبيمـار، فيبروز قابل توجه (FibroScan > 7.2 kPa) و در دو نفر فيبروز شديد ( FibroScan> 9/6 kPa) مشاهده شد. هنگامى كه بيماران بر اساس وجود فيبروز كبدى در آنها به r

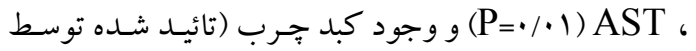

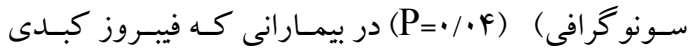

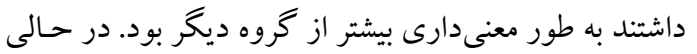
كه در مقايسه دوز تجميعى MTX ( (P=•/T) و مدت زمان

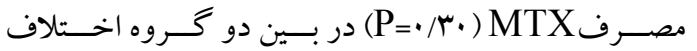
معنى دارى مشاهده نشد (جدول Y). نتايج مربوط به تجزيسه و

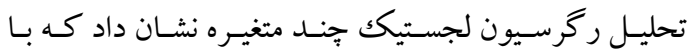
افزايش ميزان ALT، شانس بروز فيبروز در بيماران مبتلا بـهـ

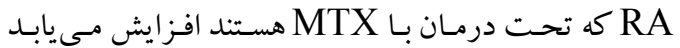
$(\mathrm{OR}=1.07 ; 95 \% \mathrm{CI}: 1.01$ to $1.13 ; \mathrm{p}=$

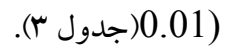

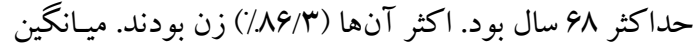
مدت زمان ابتلا به بيمارى در آنها 9 سال (در محـدوده Y تا 9 سال) و ميانه (صدك 9 (YD-VD) فعاليت بيمارى اندازه گيرى

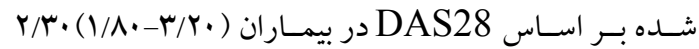
محاسبه گرديد.

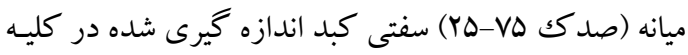

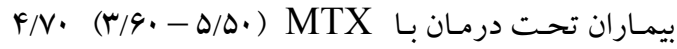

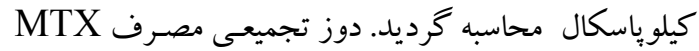

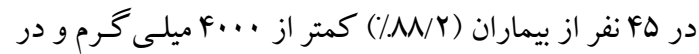

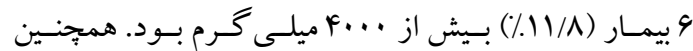

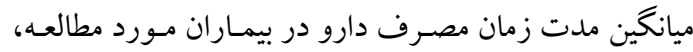
. در بررسى رابطه بين متغيرهاى مورد بررسى با فيبروز كبدى،

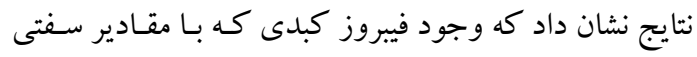
كبد اندازه گيرى شده در فيبرواسكن برابر يا بيشتر از 4 كيلو

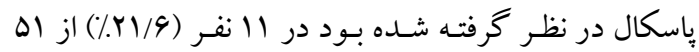

\begin{tabular}{|c|c|}
\hline $\begin{array}{l}\text { تمام بيماران } \\
(n=01)\end{array}$ & متغيرها \\
\hline$\Delta r / \Delta r \pm q / q \Delta$ & سن (سال) \\
\hline $\operatorname{FF}(\% / \Lambda g / \Gamma)$ & زن - ت ان \\
\hline$r V / \cdot r \pm r / V F$ & BMI, $\mathrm{kg} / \mathrm{m}^{2}$ \\
\hline$r F / \cdots(|N / \cdots-r| / \cdots)$ & $\mathrm{ALT}, \mathrm{IU} / \mathrm{L}$ \\
\hline$r \cdot / \cdots(19 / \cdots-r V / \cdots)$ & AST, IU/L \\
\hline $19 \% / \cdot r \pm \Delta r / V \Lambda$ & ALK, IU/L \\
\hline$r / r \cdot(1 / \Lambda \cdot-r / r \cdot)$ & DAS28 \\
\hline$\Delta F / / F \pm F \cdot / q F$ & مدت زمان مصرف MTX (ماه) \\
\hline$r / v \cdot(r / 4 \cdot-\Delta / \Delta \cdot)$ & سفتى كبد (kPa) \\
\hline$r \mu F / \mu T \Delta V / \mu r$ & استئاتوز كبد(dB/m) \\
\hline $11(\% / Y / 9)$ & كبد جرب (تائيد شده توسط سونو گر افى) \\
\hline $19(\% \mathrm{rV} / \mathrm{T})$ & 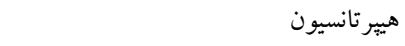 \\
\hline
\end{tabular}


|ع سميره (مضانى

جدول Y. مقايسهاى خصوصيات دمو گرافيك، بالينى و بيوشيميايى بين دو گروه از بيماران (بر اساس اندازه گيرى سفتى كبد)

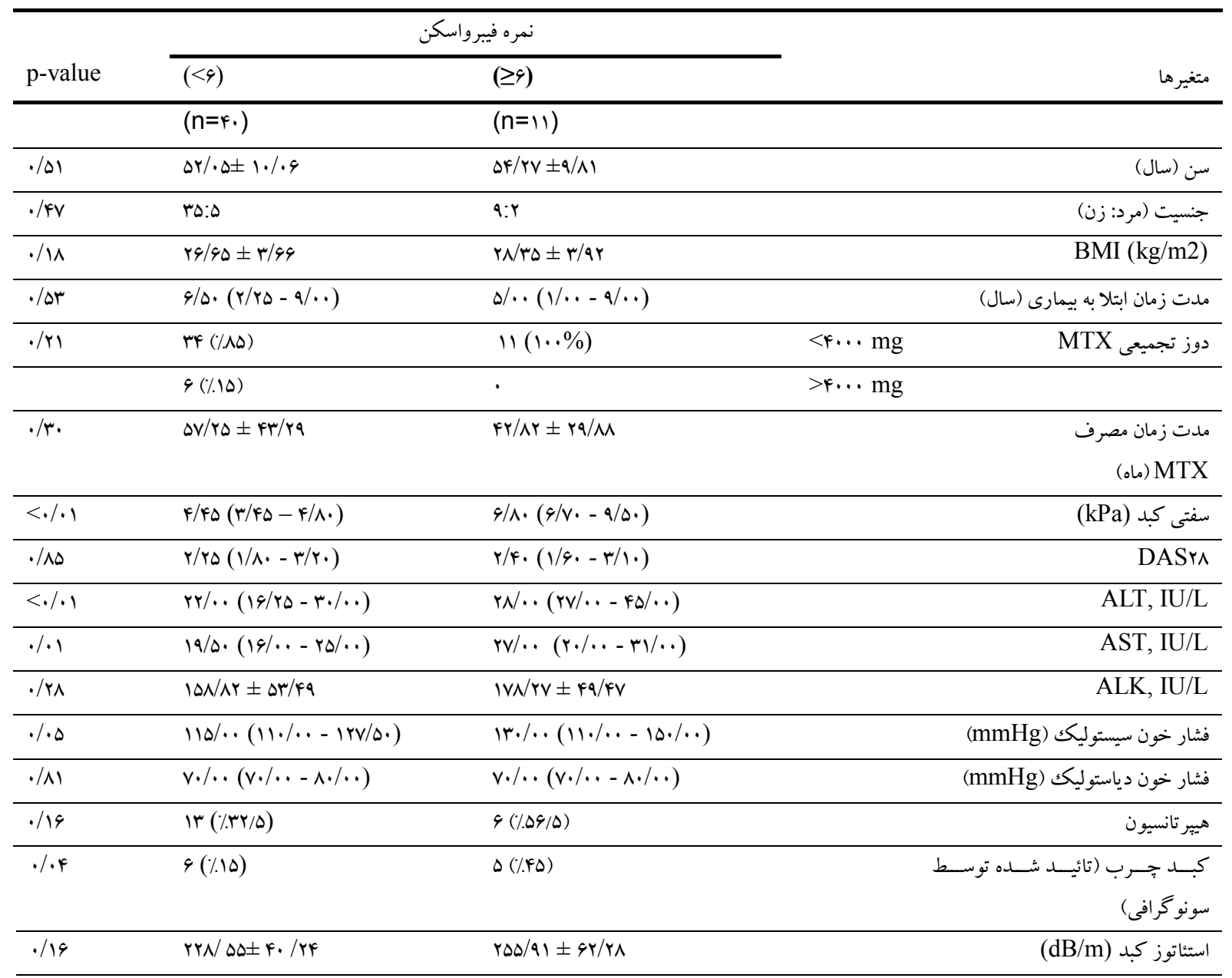

\begin{tabular}{|c|c|c|c|}
\hline Pvalue & $\begin{array}{l}95 \% \text { confidence } \\
\text { interval }(\mathrm{CI})\end{array}$ & OR & متغيرهاى مستقل \\
\hline$\cdot / M r$ & $.199-1 / .9$ & $1 / \cdot r$ & فشار خون سيستوليك \\
\hline$\cdot / \mathrm{TV}$ & $. / 49-10 / .1$ & r/94 & كبد جرب (تائيد شده توسط سونو گرافى) \\
\hline$\cdot / \wedge$. & $\cdot / 9 \cdot-1 / 10$ & $1 / \cdot 1$ & AST \\
\hline.$/ \cdot 1$ & $1 / \cdot 1-1 / 1 r$ & $1 / \cdot v$ & ALT \\
\hline
\end{tabular}


مطالعه بر خلاف دو مطالعه قبلى افراد خاق و مصرف كننده

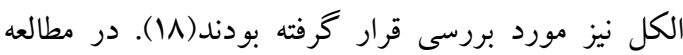
حاضر نيز مصرف طولانى مدت دارو با افزايش ريسك

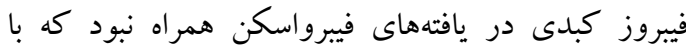
مطالعات انجام شده فوق همخوانى دارد. در مطالعه حاضر در ץ نفر (q/\%/\%) از بيماران فيبروز FibroScan score قابلتوجه و شديد مشاهده گرديد > 7.2 Kapa در مطالعه مشابه نيز از •19 بيمار مبتلا به RA تحت درمان طY طو لانىمدت با MTX بانه مصرف دوز تجميعى ميلى گرم (range 2340, 18,200 mg; IQR 2795) ، تنها در rا نفر (ه/ه/) از آنها فيبروز قابلتوجه گزارش شد(IV)؛ بنابراين، بروز فيبروز شديد كبدى يا سيروز اندازه

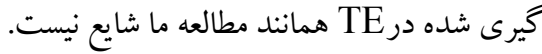

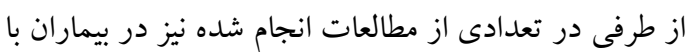

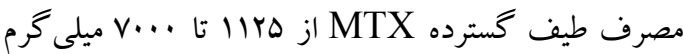
كه تحت بيويسى كبد قرار گرف فتند، فيبروز كبدى قابل توجه

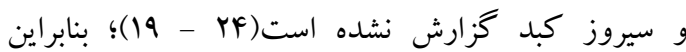
يافتههاى اين مطالعه با ديخر مطالعات كه در آن فيبروز كبدى با بيويسى سوزنى ارزيابى شده است تأييد مىشود. با باليا

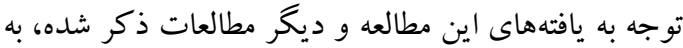
نظر مىرسد كه فيبروز كبدى قابل توجه يا سيروز كبد يكى نيخرانى عمده در درمان با MTX نيست. همجنين مى تواند به عنوان يكك ابزار غيرتهاجمى بر باى ارزيابى فيبروز

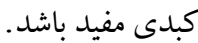

شيوع پايين فيبروز قابلتوجه را ميتوان توسط عوامل

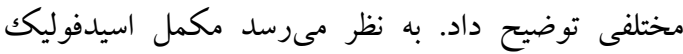

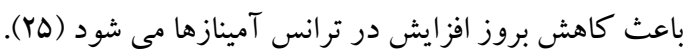
استفاده از دوز كمتر و مصرف هفتخى به جاى روزانه از باز

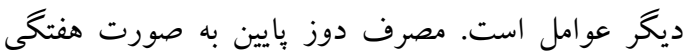

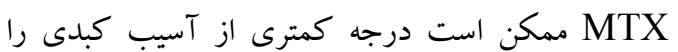
ايجاد كند و زمان كافى براى كبد جهت بهبود و بازسازى
تأثير مصرف طولانى مدت MTX بر فيبروز كبد همجنان

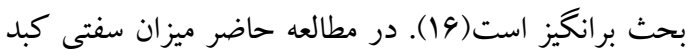
در اه نفر از بيماران مبتلا به RA كه به طور ميانكين برانير

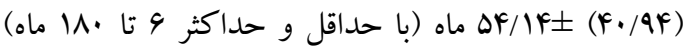
تحت درمان با مصرف هفتگى MTX بودند، توسط متد الاستو گرافى گذرا مورد ارزيابى قرار كرفت. يافتههاى اصلى اين مطالعه حاكى از اين است كه افزايش مدت زمان مصرف و دوز تجميعى MTX تأثيرى در بروز فيبروز كبدى ندارد؛ اما شانس بروز فيبروز كبدى با افزايش ميزان ALT افزايش مىيابد و تفاوت معنىدارى در مقادير سرم بين بيماران باو بدون فيبروز كبدى وجود دارد.

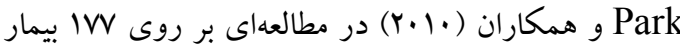
مبتلا به RA كه تحت درمان با MTX به مدت بيش از سه سال بودند، افراد از نظر داشتن فيبروز كبدى توسط TE مورد بررسى قرار گرفتند. بيماران در اين مطالعه از نظر مصرف دوز تجميعى دارو به دو گروه دريافت كننده دوز

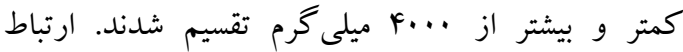
معنى دارى بين ميزان درجه سفتى كبد (كايا) در دو گروه مشاهده نشد. همجنين بين ميزان درجه سفتى كبد اندازه كيرى شده با TE و دوز تجميعى مصرف دارو ارتباط معنى دارى مشاهده نشد اما همبستخى معنىدارى بين مقادير

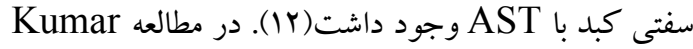
و همكاران (Y.11) شامل •19 بيمار مبتلا به RA كه به

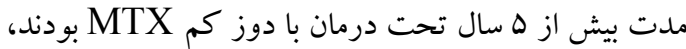
ارتباط معنىدارى بين مدت زمان مصرف و دوز تجميعى دارو با فيبروز كبدى بررسى شده توسط TE مشاهده

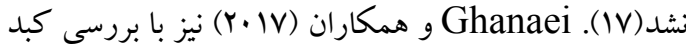
1.انفر از بيماران مبتلا به يسوريازيس و RA توسط TE كه حداقل دو سال تحت درمان با متوتروكسات بودند، ارتباط معنىدارى بين وجود فيبروز كبدى با دوز تجميعى و

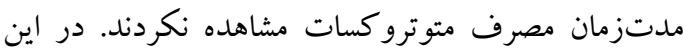




$$
\begin{aligned}
& \text { بود. با توجه به عدم انجام فيبرو اسكن قبل از شروع درمان } \\
& \text { آسيب وجود داشته باشد(YVو YY). مصرف بيشازحد الكل، }
\end{aligned}
$$

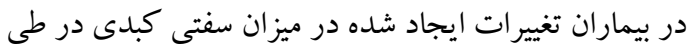

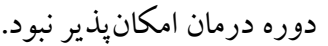

$$
\begin{aligned}
& \text { جاقى، وجود ديابت به عنوان عوامل خطر تأثير گذار براى }
\end{aligned}
$$

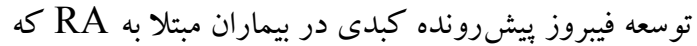

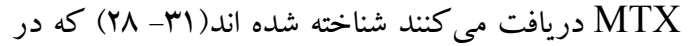

$$
\begin{aligned}
& \text { نتيجه كيرى } \\
& \text { اين مطالعه افرادى كه اين شرايط را دارا بودند از مطالعه } \\
& \text { مطالعه حاضر نشان مىدهد كه فيبروز قابلتوجه و شديد } \\
& \text { كبدى در بيماران تحت درمان با متوتروكسات ناشايع است } \\
& \text { و افزايش مدت زمان مصرف متوتروكسات و دوز تجميعى } \\
& \text { دارو تاثيرى بر افزايش بروز آن ندارد. ميزان بروز فمان فيبروز }
\end{aligned}
$$

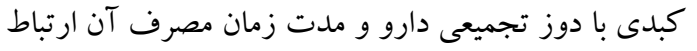

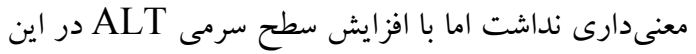

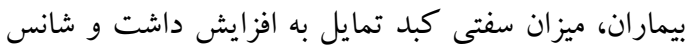

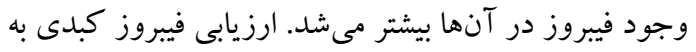

$$
\begin{aligned}
& \text { صورت سريال توسط متد الاستو گرافى جهت بيماران } \\
& \text { ارتريت روماتوئيد تحت درمان با متوتروكسات توصيه مى - }
\end{aligned}
$$

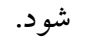

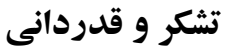

$$
\begin{aligned}
& \text { اين مقاله حاصل باياننامه با عنوان (بررسى ميزان فيبروز كبد }
\end{aligned}
$$

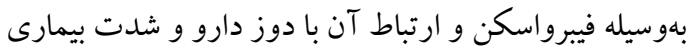

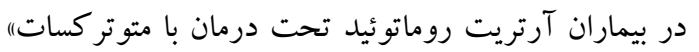

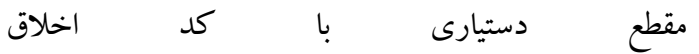

$$
\begin{aligned}
& \text { IR.MUK.REC.1396/297 مربوط به خانم دكتر } \\
& \text { سميره رمضانى كه با حمايت مالى معاونت تحقيقات و } \\
& \text { فناورى دانشگاه علوم يزشكى كردستان انجام شده است. }
\end{aligned}
$$

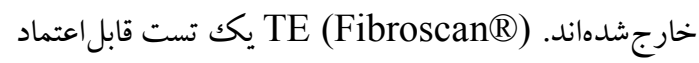

$$
\begin{aligned}
& \text { در ارزيابى فيبروز و سيروز كبدى با اندازه گيرى سفتى كبد }
\end{aligned}
$$

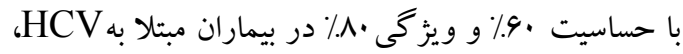

$$
\begin{aligned}
& \text { NASH و RA HBV } \\
& \text { حال جاقى و ميزان بالاى ALT سبب كاهش حساسيت اين }
\end{aligned}
$$

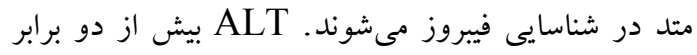

$$
\begin{aligned}
& \text { طبيعى مى تواند در اندازه گيرى TE تداخل ايجاد كند (MF). } \\
& \text { در مطالعه ما سطح ALT در هيج كدام از بيماران دو برابر } \\
& \text { حد نرمال نبود. در نتيجه مقادير سفتى كبد تحت تأثير سطح } \\
& \text { ALT نمىباشد. } \\
& \text { نتايج مطالعه ما نشان داد كه افزايش ALT يكك عامل خطر }
\end{aligned}
$$

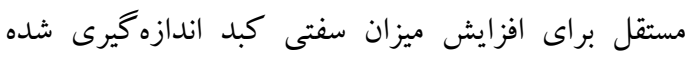

$$
\begin{aligned}
& \text { توسط TE مىباشد و مىتواند بيانكر اين باشد كه اين مئن }
\end{aligned}
$$

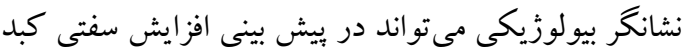

$$
\begin{aligned}
& \text { و بيشرفت فيبروز كبدى كمكك كننده باشد. } \\
& \text { يكى از محدوديتهاى مطالعه اين بود كه هيج كدام از }
\end{aligned}
$$

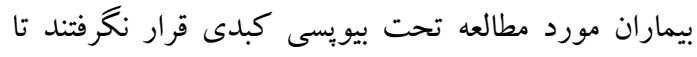

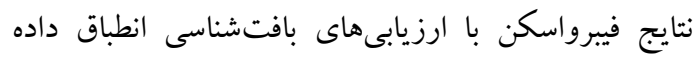

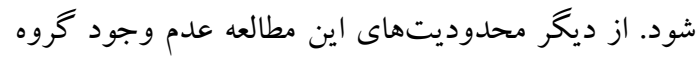

$$
\begin{aligned}
& \text { كنترل و مقايسه نتايج فيبرواسكن آنها با افراد تحتدرمان إندان }
\end{aligned}
$$

\section{References}

1.Turesson C, Matteson EL. Management of extra-articular disease manifestations in rheumatoid arthritis. Curr Opin Rheumatol. 2004; 16(3):206-11.

2.Guo Q, Wang Y, Xu D, Nossent J, Pavlos NJ, Xu J. Rheumatoid arthritis: pathological mechanisms and modern pharmacologic therapies. Bone Res. 2018; 6:15 .

3.Weinblatt ME. Methotrexate in rheumatoid arthritis: a quarter century of development. Trans Am Clin Climatol Assoc. 2013;124:16-25.

4. Smolen JS, Landewé R, Breedveld FC, Buch M, Burmester G, Dougados M, et al. EULAR recommendations for the management of rheumatoid arthritis with synthetic and biological disease-modifying antirheumatic drugs: 2013 update. Ann Rheum Dis. 2014; 73(3):492-509. 
5.Singh JA, Furst DE, Bharat A, Curtis JR, Kavanaugh AF, Kremer JM, et al. 2012 update of the 2008 American College of Rheumatology recommendations for the use of disease-modifying antirheumatic drugs and biologic agents in the treatment of rheumatoid arthritis. Arthritis Care Res (Hoboken). 2012; 64(5):625-39.

6.Aithal GP. Hepatotoxicity related to antirheumatic drugs. Nat Rev Rheumatol. 2011; $7(3): 139$.

7.Baghbanian M, Amirbaigy MK, Salmanroghani H, Baghbanian A. Methotrexate Hepatotoxicity the Danger Not to Be Ignored. SSU_Journals. 2013; 21(2):257-64.

8.Te Helen S, Schiano TD, Kuan SF, Hanauer SB, Conjeevaram HS, Baker AL. Hepatic effects of long-term methotrexate use in the treatment of inflammatory bowel disease. The Am J Gastroenterol. 2000; 95(11):3150-6.

9.Castera L. Invasive and non-invasive methods for the assessment of fibrosis and disease progression in chronic liver disease. Best Pract Res Clin Gastroenterol. 2011; 25(2):291-303.

10.Jung KS, Kim SU. Clinical applications of transient elastography. Clin Mol Hepatol. 2012; 18(2): 163.

11.Arena U, Stasi C, Mannoni A, Benucci M, Maddali-Bongi S, Cammelli D, Assarat A, Marra F, Pinzani M. Liver stiffness correlates with methotrexate cumulative dose in patients with rheumatoid arthritis. Dig Liver Dis. 2012; 44(2):149-53.

12.Park SH, Choe JY, Kim SK. Assessment of liver fibrosis by transient elastography in rheumatoid arthritis patients treated with methotrexate. Joint Bone Spine. 2010; 77(6):588-92.

13.Villeneuve E, Nam J, Emery P. 2010 ACR-EULAR classification criteria for rheumatoid arthritis.

14.Tsochatzis EA, Gurusamy KS, Ntaoula S, Cholongitas E, Davidson BR, Burroughs AK. Elastography for the diagnosis of severity of fibrosis in chronic liver disease: a meta-analysis of diagnostic accuracy. J Hepatol. 2011; 54(4):650-9.

15.Bray AP, Barnova I, Przemioslo R, Kennedy C. Liver fibrosis screening for patients with psoriasis taking methotrexate: a cross-sectional study comparing transient elastography and liver biopsy. Br J Dermatol. 2012;166(5):1125-7.

16. Tang H, Neuberger J. Methotrexate in gastroenterology-dangerous villain or simply misunderstood? Aliment Pharmacol Ther. 1996 Oct;10(6):851-8.

17.Kumar A, Vasdev V, Manrai M, Bhayana A, Hegde A, Arjun MN, Kishore K. Assessment of hepatic fibrosis in patients with rheumatoid arthritis on long-term methotrexate therapy using transient elastography. Indian J Rheumatol. 2018; 13(4):246.

18. Mansour-Ghanaei F, Erfani A, Shafaghi A, Joukar F, Hajiabasi A, et al. Transient Elastography in Methotrexate Administered Patients. Hepat Mon. 2017; 17(8):e57917.

19. Kremer JM, Tolman K, Samowitz W. Long-term prospective sequential liver biopsies in patients with rheumatoid arthritis on weekly oral methotrexate. Arthritis Rheum. 1990;33(suppl 9):S40.

20.Brick JE, Moreland LW, Al-Kawas F, Chang WW, Layne RD, DiBartolomeo AG. Prospective analysis of liver biopsies before and after methotrexate therapy in rheumatoid patients. InSeminars in arthritis and rheumatism 1989 Aug 1 (Vol. 19, No. 1, pp. 31-44). WB Saunders.

21.Rau R, Karger T, Herborn G, Frenzel H. Liver biopsy findings in patients with rheumatoid arthritis undergoing longterm treatment with methotrexate. J Rheumatol. 1989; 16(4):489-93 22. Shergy WJ, Polisson RP, Caldwell DS, Rice JR, Pisetsky DS, Allen NB. Methotrexateassociated hepatotoxicity: retrospective analysis of 210 patients with rheumatoid arthritis. Am J Med. 1988; 85(6):771-4. 
23. Willkens RF, Leonard PA, Clegg DO, Tolman KG, Ward JR, Marks CR, et al. Liver histology in patients receiving low dose pulse methotrexate for the treatment of rheumatoid arthritis. Ann Rheum Dis. 1990; 49(8):591-3.

24.Kremer JM, Lee RG, Tolman KG. Liver histology in rheumatoid arthritis patients receiving long-term methotrexate therapy. A prospective study with baseline and sequential biopsy samples. Arthritis Rheum. 1989; 32(2):121-7.

25.Van Ede AE, Laan RF, Rood MJ, Huizinga TW, Van De Laar MA, Denderen CJ, et al. Effect of folic or folinic acid supplementation on the toxicity and efficacy of methotrexate in rheumatoid arthritis: A forty-eight-week, multicenter, randomized, double-blind, placebo-controlled study. Arthritis Rheum. 2001 Jul;44(7):1515-24.

26. Hall PD, Jenner MA, Ahern MJ. Hepatotoxicity in a rat model caused by orally administered methotrexate. Hepatol. 1991;14:906-10.

27.Kaplan MM. Methotrexate hepatotoxicity and the premature reporting of Mark Twain's death: Both greatly exaggerated. Hepatol. 1990;12:784-6.

28.Laharie D, Zerbib F, Adhoute X, Boue-Lahorgue X, Foucher J, Castera L, et al. Diagnosis of liver fibrosis by transient elastography (FibroScan) and non-invasive methods in Crohn's disease patients treated with methotrexate. Aliment Pharmacol Ther. 2006; 23(11): 1621 -8.

29.Schmajuk G, Miao Y, Yazdany J, Boscardin WJ, Daikh DI, Steinman MA. Identification of risk factors for elevated transaminases in methotrexate users through an electronic health record. Arthritis Care Res (Hoboken). 2014; 66:1159-1166.

30. Salliot C, van der Heijde D. Long-term safety of methotrexate monotherapy in patients with rheumatoid arthritis: a systematic literature research. Ann Rheum Dis. 2009; 68:11001104.

31.Sotoudehmanesh R, Anvari B, Akhlaghi M, Shahraeeni S, Kolahdoozan S. Methotrexate hepatotoxicity in patients with rheumatoid arthritis. Middle East J Dig Dis. 2010; 2:104-109

32.Berends MA, Snoek J, de Jong EM, et al. Liver injury in long-term methotrexate treatment in psoriasis is relatively infrequent. Aliment Pharmacol Ther. 2006; 24:805 -811

33.Maybury CM, Jabbar-Lopez ZK, Wong T, Dhillon AP, Barker JN, Smith CH. Methotrexate and liver fibrosis in people with psoriasis: a systematic review of observational studies. Br J Dermatol. 2014;171:17-29.

34.European Association for the Study of the Liver. EASLE-ALEH Clinical practice guidelines: non-invasive tests for evaluation of liver disease severity and prognosis. J Heptaol. 2015; 63:237-264. 